\title{
CORN STARCH DOPED WITH SODIUM IODATE AS SOLID POLYMER ELECTROLYTES FOR ENERGY STORAGE APPLICATIONS
}

\author{
Fatin Farhana Awang, Mohd Faiz Hassan*, \\ KhadiJah Hilmun Kamarudin
}

\author{
Universiti Malaysia Terengganu, Faculty of Science and Marine Environment, Ionic State Analysis (ISA) \\ Laboratory, Advanced Nano-Materials (ANoMa) Research Group, 21030 Kuala Nerus, Terengganu, Malaysia \\ * corresponding author: mfhassan@umt.edu.my
}

\begin{abstract}
The concern about environmental problems has inspired a of energy storage devices from natural sources. In this study, solid polymer electrolyte (SPE) films made from corn starch doped with different compositions of sodium iodate $\left(\mathrm{NaIO}_{3}\right)$ were prepared via the solution casting technique. The effect of dopants on the structure, morphology and electrical properties of SPE films was analysed using X-Ray diffraction (XRD), scanning electron microscopy (SEM) and electrochemical impedance spectroscopy (EIS) analysis. From the XRD, it shows that the amorphous state would influence the conductivity values of SPE films. Then, the SEM observations revealed that the films seem to be rough, porous and having branch structure, which may affect the conductivity of SPE films. The maximum conductivity of SPE film is obtained from 3 wt. $\%$ of $\mathrm{NaIO}_{3}$ with a value of $1.08 \times 10^{-4} \mathrm{Scm}^{-1}$ at room temperature $(303 \mathrm{~K})$. From the results, this SPE is proposed to have a great potential in future energy storage applications.
\end{abstract}

KEYWORDS: Biodegradable polymers, polymer membranes, solid polymer electrolytes, sodium salt, electrical properties.

\section{INTRODUCTION}

Electrolyte is one of the main components in battery, which has been used as a medium for ion movement between anode and cathode. It can be divided into liquid and solid electrolytes. According to [1], there are a few limitations of liquid electrolytes, such as leakage issues and the difficulty to store and produce them. In order to solve the arising problems, solid polymer electrolyte (SPE) has been considered. The important criteria in the selection of SPE include stability and safety, reduction in cost and weight, and flexibility, which is easy to be fabricated and could perform as a proper medium for electrode-electrolyte contact [2 6]. Furthermore, it is seen suitable to be applied in some applications of electronic devices such as batteries, solar cell, sensors and supercapacitors [711. However, the main barrier that makes SPE hard to be utilised is the relatively low ionic conductivity at ambient temperature. Normally, the ion conduction usually takes place in the amorphous region [12]. This is because the amorphous phase provides free spaces for the ions to move along with the polymer matrix. Many efforts have been suggested to enhance the ionic conductivity of polymer electrolytes, which includes incorporating various ionic dopant with host polymers [13].

The usage of biodegradable polymers is vital as they can be decomposed by a natural agent easily. Besides, they also take a short duration to decay as compared to non-biodegradable ones without leaving any electronic waste. Some examples of polymers, such as chitosan, starch, pectin and cellulose [14 16] are usually used in certain areas. It is commonly used as a host for the preparation of solid polymer electrolyte (SPE) due to its properties, such as being renewable, cheaper, non-toxic and soluble in water 17 . 20. In the SPE preparation, starches are used as host polymers and sodium iodate $\left(\mathrm{NaIO}_{3}\right)$ as an ionic dopant. Basically, starches are carbohydrate polymers that consist of amylose and amylopectin, which are bonded together [21]. However, the starch chains are held together by hydrogen bond, making them insoluble in cold water. Then, to obtain corn starch thin films, starch granules should be incorporated with a plasticizer in excess water at temperatures below $100{ }^{\circ} \mathrm{C}$. Examples of commonly used plasticizers are glucose, glycerol and sorbitol [22]. According to [23], glycerol is the most suitable plasticizer because of its mechanical characteristics and transparency. Also, the increase in glycerol contents can promote mobile ions to penetrate the polymer matrix. From this, it will facilitate the rise in amorphicity of the electrolyte and thus, leads to an increase in conductivity 24 .

Salts act as an important constituent to an electrolyte as they have a strong influence on the electrolyte properties such as conductivity and thermal stability. In this study, sodium $(\mathrm{Na})$ salts were selected as a well-established candidate due to their material abundance, low cost and environmentally friendliness 25 27. Moreover, sodium also exhibits similar chemical properties to lithium that are applied 

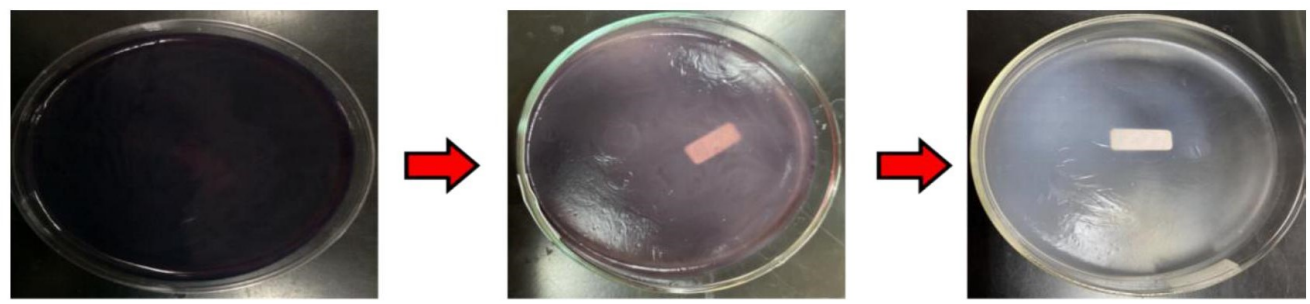

Figure 1. The physical changes of the SPE films.

in battery applications. Meanwhile, lithium (Li) materials themselves are very hazardous and the sources are very limited. Thus, the purpose of this study is to investigate the morphology and electrical properties of corn starch doped with sodium iodate $\left(\mathrm{NaIO}_{3}\right)$ by using the X-ray diffraction (XRD), scanning electron microscopy (SEM) and electrical impedance spectroscopy (EIS) techniques.

\section{EXPERIMENTAL}

\subsection{MATERIALS}

The solution casting technique was used to prepare corn-starch-based polymer electrolyte. Sodium iodate, $\mathrm{NaIO}_{3}$, (purity $96 \%$, Sigma-Aldrich) and corn starch, $\mathrm{C}_{6} \mathrm{H}_{10} \mathrm{O}_{5}$, (Sigma-Aldrich) were used as the raw materials. In addition, two different solvents $(20 \mathrm{ml}$ of distilled water and $0.6 \mathrm{ml}$ of glycerine) with a purity of $100 \%$ and $96 \%$ were also used.

\subsection{Preparation of SPE films}

SPE was prepared via the solution casting method. Different amounts of $\mathrm{NaIO}_{3}$ (wt. \%), which range from $0,1,3,5,7$ and 9 , were dissolved in the mixed solvents (distilled water and glycerine) until a complete dissolution. The weight percentage was calculated using the formula expressed in Equation 1.

$$
w t . \%=\frac{x}{x+y} x 100
$$

Where, $x$ is the weight of salt $(\mathrm{g}), y$ is the weight of the polymer and weight percentage is the difference values in percentage for salt as a dopant.

Thereafter, $1 \mathrm{~g}$ of corn starch was added into the solution and continuously stirred at $60-70{ }^{\circ} \mathrm{C}$, until it turned homogenous with no phase separation. The solution was poured into glass petri dishes and left at room temperature for the SPE to be formed. For further drying process, the SPE films were kept in a desiccator filled with silica gels to eliminate any excess moisture.

\subsection{Characterisation technique}

$\mathrm{X}$-ray diffraction (XRD) is a technique to determine the structural changes in a polymer electrolyte system. The crystallinity or amorphousness of the polymer electrolyte systems was observed using a MiniFlex II diffractometer with $\mathrm{CuK} \alpha$ radiation. The $2 \theta$ angle varies from $10^{\circ}$ to $60^{\circ}$ with a step size of $5 \%$ min per SPE film samples. Then, the obtained data were analysed using the Search-Match and Origin software. The degree of crystallinity $\left(\chi_{c}\right)$ of the SPE films was calculated from Equation 2

$$
\text { Crystallinity }(\%)=\frac{A_{c}}{A_{C}+A_{m}} \times 100
$$

Where, $A_{c}$ and $A_{m}$ are the crystalline and amorphous areas, respectively.

Scanning electron microscopy (SEM) was used for a morphological investigation. For this purpose, SPE films were coated to make them conductive for a better observation and placed on specimen tubs with double cellophane. They were examined using the Model JEOL JSM-6350LA with an acceleration voltage of $20 \mathrm{kV}$ at room temperature. The images were taken at various magnifications of $\times 350, \times 750$ and $\times 1000$. Through this method, the structure of the SPE films can be directly observed.

The electrical properties of prepared films were observed by the electrochemical impedance spectroscopy (EIS) technique. The thickness of the SPE films was measured using a digital micrometre screw gauge. Furthermore, the impedance of SPE films was determined using a HIOKI 3532-50 LCR Hi-Tester at room temperature, which is interfaced to a computer over a frequency range of $50 \mathrm{~Hz}$ to $1 \mathrm{MHz}$. The films were cut into appropriate size $(3.0 \mathrm{~cm} \times 1.0 \mathrm{~cm})$ and placed between two stainless blocking electrodes. The values of bulk resistance, $R_{b}$ obtained from the measurement were used to calculate the conductivity, $\sigma$ using Equation 3 respectively.

$$
\sigma=\frac{l}{R_{b} A}
$$

Where, $l$ is the thickness of SPE films, $R_{b}$ is the bulk resistance achieved from the interception of imaginary impedance against real impedance and $A$ is the contact area of electrode-electrolyte.

\section{Results AND DisCUssion}

The physical image of the corn starch- $\mathrm{NaIO}_{3} \mathrm{SPE}$ films can be seen in Figure 1. It was observed that an insertion of $\mathrm{NaIO}_{3}$ salt into the polymer electrolyte 
had changed the homogenous solution into dark purple after being cooled at room temperature. Then, the SPE films were left to be dried naturally for 24 hours until pale purple thin films were formed. By increasing the drying time, the SPE films had shifted to colourless. From this, it could be considered that the changes in SPE film features might alter the structure and its morphology. Moreover, the difference in colour or transparency might be caused by the changes in internal structures developed during the drying of the films [28. The thickness of the SPE films was measured in a range of $0.104 \mathrm{~mm}$ to $0.124 \mathrm{~mm}$. It slightly varied due to the viscosity of the polymer solutions.

The XRD is a technique used to identify the changes of phases in SPE film whether in amorphous or crystalline regions [29]. Figure 2 displays the XRD of SPE films. From the results, it can be seen that the pure corn starch film showed a broad hump at $15^{\circ}$ to $28^{\circ}$, which corresponded to the amorphous nature of the polymer 30. Furthermore, as seen in all patterns, the addition of $\mathrm{NaIO}_{3}$ into the polymer electrolyte would give no significant change except for the higher salt content. Specifically, with 1 wt. $\%$ of $\mathrm{NaIO}_{3}$, the pattern of complex films changed to a wider hump as compared to the pure corn starch film with $68 \%$ of amorphicity. Then, the incorporation of $3 \mathrm{wt} . \%$ of $\mathrm{NaIO}_{3}$ showed a pattern similar to the complex film that contained 1 wt. $\%$ of $\mathrm{NaIO}_{3}$ but the amorphous phase had increased to $77 \%$. The amorphicity started to decrease with a further addition of $\mathrm{NaIO}_{3}$. This might be caused by the interaction between the sodium salt and polymer host, which altered the film's state. It could be seen that the amorphousness of the SPE films started to decrease for samples containing 5 wt. $\%$ and 7 wt. $\%$ of $\mathrm{NaIO}_{3}$ with a value of $58 \%$ and $40 \%$, respectively. Thereafter, several crystalline peaks appeared at $2 \theta=14.3^{\circ}, 21.4^{\circ}, 24.9^{\circ}, 27.1^{\circ}$ and $32.7^{\circ}$ for the SPE sample with 9 wt. $\%$ of $\mathrm{NaIO}_{3}$. Therefore, from the XRD results, it can be summarised that the SPE films tend to appear in the amorphous phase rather than crystalline phase. Moreover, the presence of $\mathrm{NaIO}_{3}$ did not significantly influence the formation of peaks in the complex samples.

The morphology and microstructure of SPE films were investigated by using the scanning electron microscopy (SEM). Figure 3 shows the surface images of the SPE films. In general, the surface condition played a vital role in the enhancement of conductivity and was linked with an amorphous content. In addition, according to 31] and [32, the smooth surface of the films would provide a better ionic conductivity, which correlates to the amorphous nature of the sample. It could be observed that the surface of the films became rougher with the addition of salt. The increase in the roughness and amorphous content was responsible for promoting the ion movement, hence, enhancing the conductivity. Therefore, it can be concluded that when salt was added to the polymer electrolyte, the

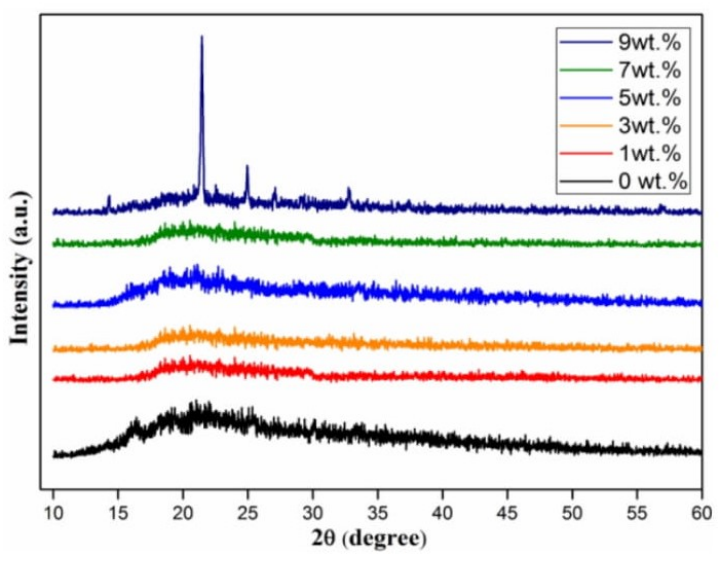

Figure 2. The X-ray diffraction pattern of corn starch doped with sodium iodate $\left(\mathrm{NaIO}_{3}\right)$.

film surface was slightly modified, which indicated that the salt was taking part in the system.

Figure 4 shows the SEM images of the prepared films. The corn starch image (Figure 4a) revealed the smooth surface and compact structure without any pores or cracks. Upon addition of 1 wt. $\% \mathrm{NaIO}_{3}$ (Figure 4b), the rough images appeared. It was clear from Figure $4 \mathrm{~b}$ that after the addition of sodium salt, the surface morphology of the SPE film changed. After increasing the salt content to $3 \mathrm{wt} . \%$ (Figure $4 \mathrm{c}$ ), the film images showed a higher number of pores with a larger diameter. It was believed that the appearance of pores could help the ions to penetrate easily through the membrane. Thus, it could lead to a rise in the conductivity. The branched structure with some pores are presented in Figure $4 \mathrm{~d}\left(5 \mathrm{wt} . \% \mathrm{NaIO}_{3}\right)$. From the figure, the number and estimated pore sizes were smaller than in the case of the previous SPE film sample. Furthermore, for SPE films that contained 7 wt.\% of $\mathrm{NaIO}_{3}$ (Figure 4 $)$ the root image did not show any salt particles present. The SPE film with the highest content of $\mathrm{NaIO}_{3}$ (9 wt.\%) appeared with some impurities and tore on the surface.

The diameter of pores for selected SPE films (Figure $4 \mathrm{c}$ - Figure 4d was analysed using ImageJ software and the results are shown in Figure 5. For the SPE film with 3 wt.\% of $\mathrm{NaIO}_{3}$, the diameter size is in the range of 5.00 to $26.01 \mu \mathrm{m}$. As stated by [33], the characteristics of pores are also to enhance the conductivity values because they could assist the ions to easier penetrate through the polymer matrix. Moreover, the larger pore size will also contribute to the higher ion penetration through the system for ion conduction. Hence, the conductivity of SPE films will increase. This is confirmed by the fact that higher conductivity values were obtained with a higher number and larger size of pores. Then, 5 wt. $\%$ of $\mathrm{NaIO}_{3}$ SPE film has shown a decrease in the amount and diameter of pores between 7.61 to $13.15 \mu \mathrm{m}$. 
(a)

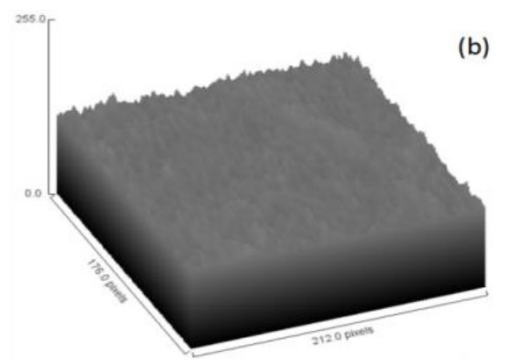

(d)

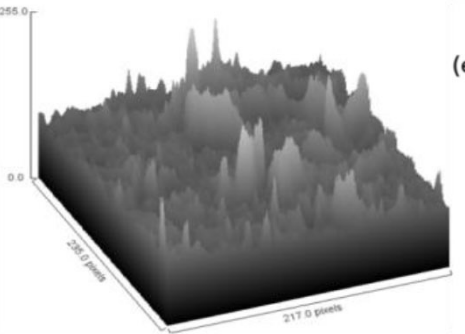

(b)

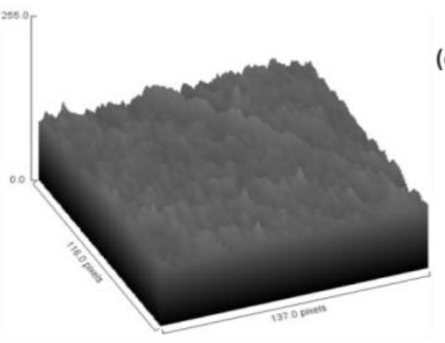

(e)

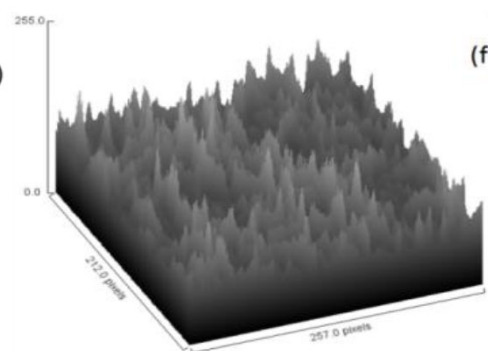

(c)

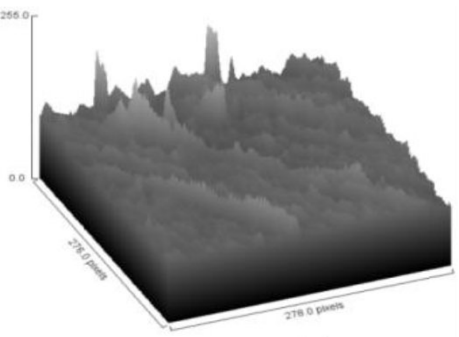

(f)

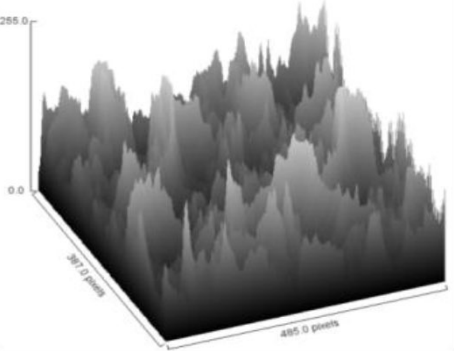

Figure 3. The surface conditions of SPE films that contain various ratios of $\mathrm{NaIO}_{3}$ (a) 0 wt.\%, (b) 1 wt.\%, (c) 3 wt.\%, (d) 5 wt. $\%$, (e) 7 wt. $\%$ and (f) 9 wt $\%$.

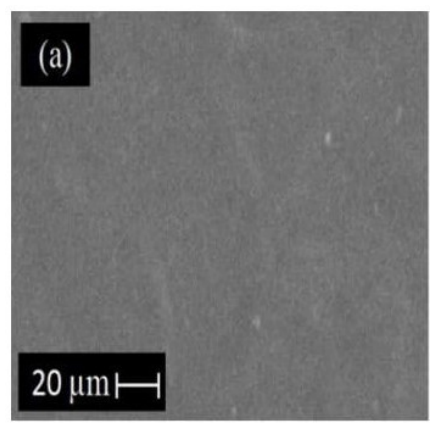

(A).

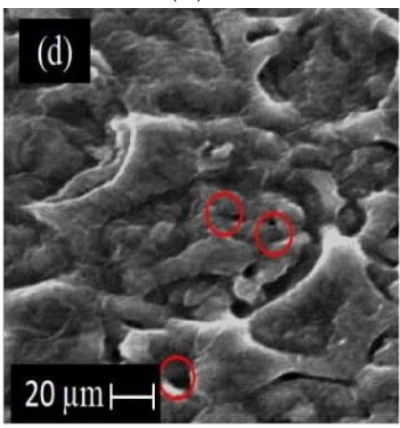

(D).

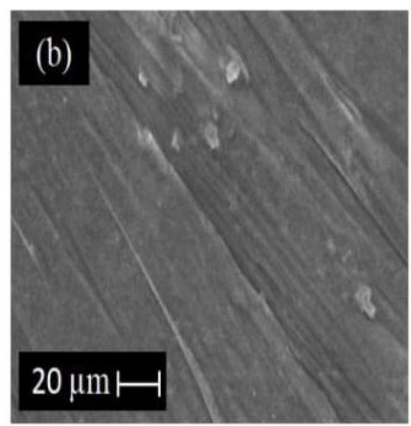

(B).

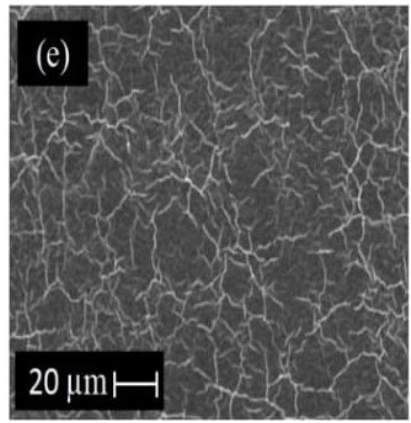

(E).

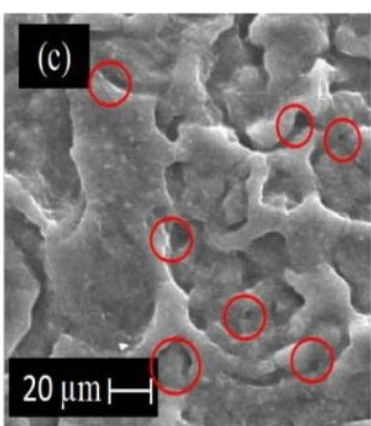

(c).

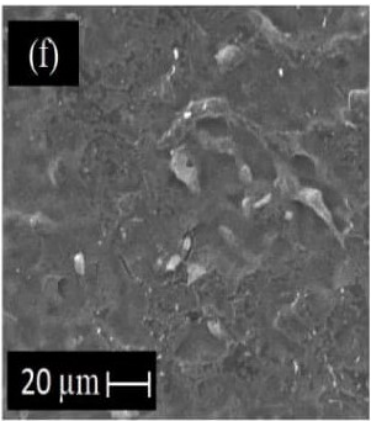

(F).

FIGURE 4. SEM micrographs of the surfaces for (a) corn starch film, (b) 1 wt. $\%$ ofNaIO 3 , (c) 3 wt.\% of $\mathrm{NaIO}_{3}$, (d) 5 wt.\% of $\mathrm{NaIO}_{3}$, (e) 7 wt.\% of $\mathrm{NaIO}_{3}$, (f) 9 wt.\% of $\mathrm{NaIO}_{3}$.

\begin{tabular}{ccc}
\hline Designation & $\begin{array}{c}\mathrm{NaIO}_{3} \text { concentration } \\
\text { (wt. \%) }\end{array}$ & $\begin{array}{c}\text { Bulk resistance, } \\
(\Omega)\end{array}$ \\
\hline $\mathrm{A}$ & 0 & $3.00 \times 103$ \\
\hline $\mathrm{B}$ & 1 & $2.00 \times 102$ \\
\hline $\mathrm{C}$ & 3 & $4.70 \times 101$ \\
\hline $\mathrm{D}$ & 5 & $1.50 \times 102$ \\
\hline $\mathrm{E}$ & 7 & $3.32 \times 102$ \\
\hline $\mathrm{F}$ & 9 & $5.00 \times 102$ \\
\hline
\end{tabular}

TABLE 1. The bulk resistance and conductivity of SPE films at different salt concentrations. 

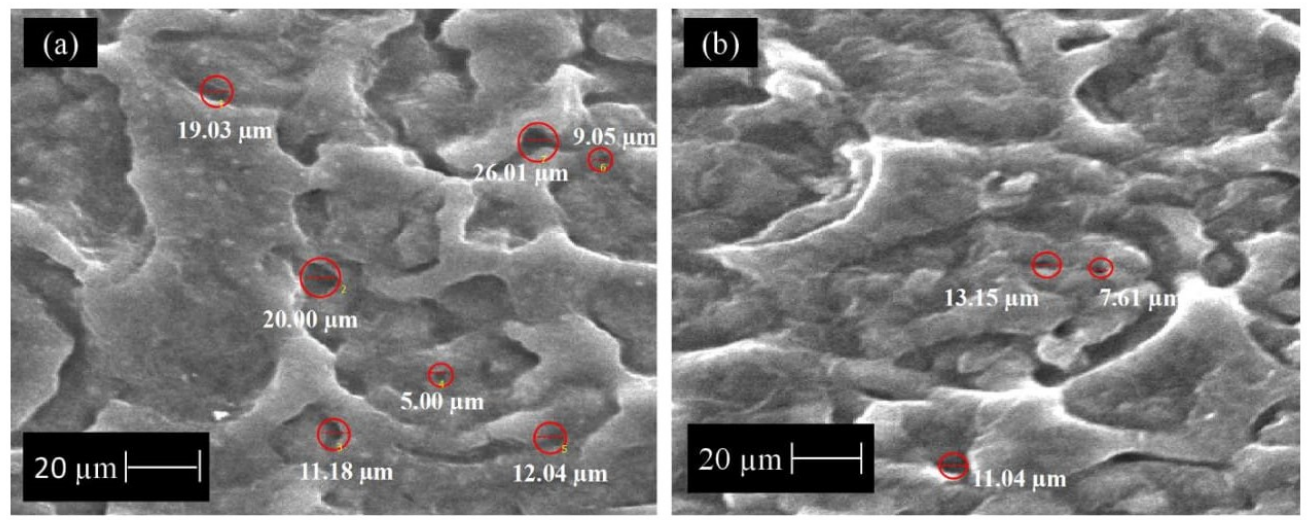

Figure 5. The SEM image of a pore in the specific location for (a) 3 wt. $\%$ of $\mathrm{NaIO}_{3}$ and (b) 5 wt.\% of $\mathrm{NaIO}_{3}$ content in SPE films .

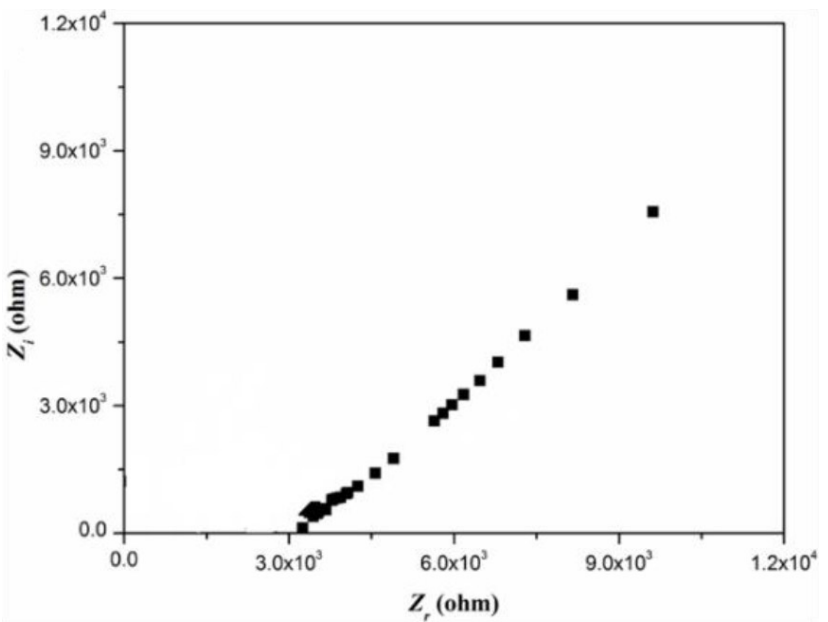

(A)

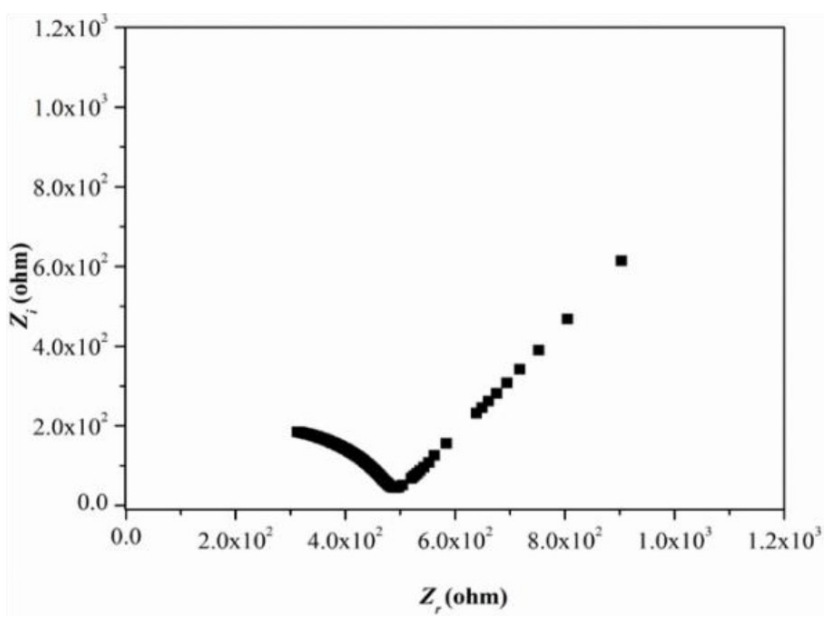

(в).

Figure 6. Cole-Cole plots for (a) 0 wt. $\%$ of $\mathrm{NaIO}_{3}$ and (b) 9 wt. $\%$ of $\mathrm{NaIO}_{3} \mathrm{SPE}$ films.

The Nyquist plot or Cole-Cole plot is a powerful technique used to better understand the electrical properties of the SPE films. Typically, the Cole-Cole plot is comprised of two semicircles. The first semicircle forms due to the contribution of the grain boundary at a low frequency and the second forms due to the grain or bulk properties at a high frequency of the material. In general, the bulk resistance $\left(R_{b}\right)$ value of the sample is determined from the plot in the interception of the higher frequency region on the $Z_{r}$ axis. Figure 6] shows the Cole-Cole plot of SPE samples containing 0 and 9 wt. $\%$ of $\mathrm{NaIO}_{3}$ while the bulk resistance values are tabulated in Table 1 A reduction of bulk resistance $\left(R_{b}\right)$ also might affect the ionic conductivity values. As the conductivity of SPE films is calculated using Equation 3, as stated before.

The best way to study the properties and mechanisms of any electrochemical reaction is by applying complex impedance spectroscopy 34]. It was observed that the conductivity of pure corn starch film was 1.1 $\times 10^{-6} \mathrm{Scm}^{-1}$. The conductivity started to increase when the sodium salt was introduced into the electrolyte system. The conductivity increased to $1.08 \times$
$10^{-4} \mathrm{Scm}^{-1}$ with the presence of $3 \mathrm{wt} . \%$ of $\mathrm{NaIO}_{3}$. It could be concluded that the rise in conductivity, as the salt content increased, was attributed to the increase in ion concentration in the polymer matrix [35. Additionally, the increase in the ion density would raise the number of free ions, which could lead to an increase in conductivity.

Further addition of salt into the electrolyte caused a decrease in conductivity. It might be due to the inability of the salt to fill the polymer host and deposit it on the surface after the films were formed 36 . This might decrease the number of mobile ions in the SPE sample, thus decreasing the conductivity. Moreover, [37] also reported that at a higher salt concentration, the distance between dissociated ions may become too small, which leads to the ions reassociating back to neutral ion pairs that do not contribute to the ion conduction. This phenomenon could be observed at a higher $\mathrm{NaIO}_{3}, 5$ wt. $\%$ - 9 wt. \% concentrations in the electrolyte will decrease the conductivity values. Figure 7 indicates the percentage of crystallinity versus conductivity for the SPE films. 


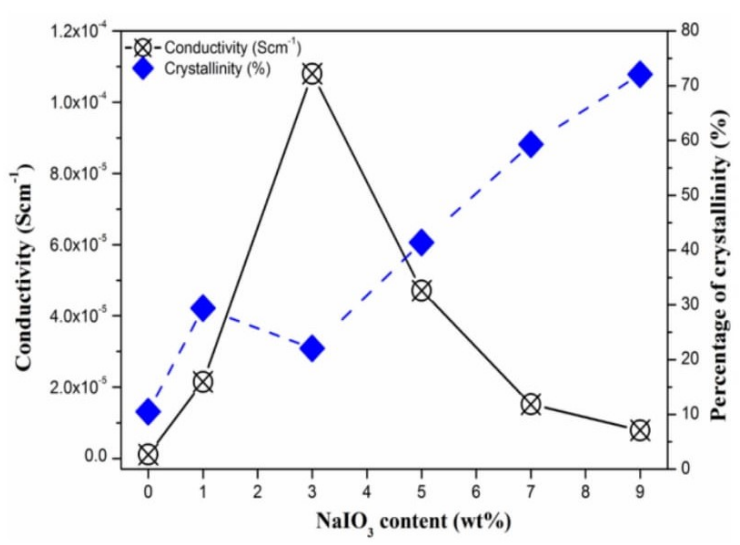

Figure 7 . The crystallinity (\%) against conductivity for each SPE film.

\section{Conclusion}

In conclusion, solid polymer electrolytes based on corn starch-NaIO3 were successfully prepared using the solution cast method. The XRD analysis proved the coexistence of peaks, which confirmed the complexation of studied materials took place. From the SEM results, it showed that doping sodium iodate with corn starch improved the structural integrity. Moreover, it can be seen that the SPE film, which contained 3 wt. $\%$ of $\mathrm{NaIO}_{3}\left(1.08 \times 10^{-4} \mathrm{Scm}^{-1}\right)$ tends to have a branch structure with some pores to enable it to facilitate the movement of free ions through the polymer electrolyte. It was also believed that the prepared SPE film had the potential to be used for energy storage applications such as in batteries as the required minimum conductivity value was achieved.

\section{ACKNOWLEDGEMENTS}

The authors acknowledge the financial support from the Ministry of Education via FRGS 2019-1 grant of (Vot. No. 59586), Faculty of Science and Marine Environment and University Malaysia Terengganu for the financial and technical support for this work to be completed.

\section{REFERENCES}

[1] A. Arya, A. L. Sharma. Effect of salt concentration on dielectric properties of $\mathrm{Li}$-ion conducting blend polymer electrolytes. Journal of Materials Science: Materials in Electronics 29(20):17903-17920, 2018. https://doi.org/10.1007/s10854-018-9905-3

[2] G. Dave, D. K. Kanchan. Dielectric relaxation and modulus studies of PEO-PAM blend based sodium salt electrolyte system. Indian Journal of Pure $\mathcal{G}$ Applied Physics 56:978-988, 2018.

[3] M. S. Mustafa, H. O. Ghareeb, S. B. Aziz, et al. Electrochemical characteristics of glycerolized PEO-based polymer electrolytes. Membranes 10(6):116, 2020. https://doi.org/10.3390/membranes 10060116

[4] M. Johnsi, S. A. Suthanthiraraj. Compositional effect of $\mathrm{ZrO}_{2}$ nanofillers on a PVDF-co-HFP based polymer electrolyte system for solid state zinc batteries. Chinese
Journal of Polymer Science 34(3):332-343, 2016. https://doi.org/10.1007/s10118-016-1750-3.

[5] M. F. Hassan, N. Noruddin. The effect of lithium perchlorate on Poly (sodium 4-styrenesulfonate): Studies based on morphology, structural and electrical conductivity. Materials Physics and Mechanics 36:8-17, 2018. https://doi.org/10.18720/MPM.3612018_2

[6] A. Chandra, A. Chandra, R. S. Dhundhel. Electrolytes for sodium ion batteries: A short review. Indian Journal of Pure \& Applied Physics 58:113-119, 2020.

[7] S. K. Deraman, N. S. Mohamed, R. H. Y. Subban. Conductivity and electrochemical studies on polymer electrolytes based on poly vinyl (chloride)- ammonium triflate -ionic liquid for proton battery. International Journal Electrochemical Science 6(1):1459-1468, 2013.

[8] M. F. Hassan, H. K. Ting. Physical and electrical analyses of solid polymer electrolytes. ARPN Journal of Engineering and Applied Sciences 13:8189-8196, 2018.

[9] C.-W. Kuo, W.-B. Li, P.-R. Chen, et al. Effect of plasticizer and lithium salt concentration in PMMA based composite polymer electrolytes. International Journal Electrochemical Science 8:5007-5021, 2013.

[10] S. G. Rathod, R. F. Bhajantri, V. Ravindhrachary, et al. Influence of transport parameters on conductivity of lithium perchlorate-doped poly(vinyl

alcohol)/chitosan composites. Journal of Elastomers $\&$ Plastics 48(5):442-455, 2016. https://doi.org/10.1177/0095244315580457.

[11] B. Jinisha, K. Anilkumar, M. Manoj, et al. Development of a novel type of solid polymer electrolyte for solid state lithium battery applications based on lithium enriched poly (ethylene oxide) (PEO)/poly (vinyl pyrrolidone) (PVP) blend polymer.

Electrochimica Acta 235:210-222, 2017. https://doi.org/10.1016/j.electacta.2017.03.118.

[12] S. B. Aziz, Z. H. Z. Abidin. Electrical conduction mechanism in solid polymer electrolytes: New concepts to arrhenius equation. Journal of Soft Matter pp. 1-8, 2013. https://doi.org/10.1155/2013/323868

[13] A. S. Samsudin, M. A. Saadiah. Ionic conduction study of enhanced amorphous solid bio-polymer electrolytes based carboxymethyl cellulose doped $\mathrm{NH}_{4} \mathrm{Br}$. Journal of Non-Crystalline Solids 497:19-29, 2018. https://doi.org/10.1016/j.jnoncrysol.2018.05.027

[14] N. H. Ahmad, M. I. N. Isa. Ionic conductivity and electrical properties of carboxylmethylcellulose $-\mathrm{NH}_{4} \mathrm{Cl}$ solid polymer electrolytes. Journal of Engineering Science and Technology 11(6):839-847, 2016.

[15] S. Çavuş, E. Durgun. Poly(vinyl alcohol) based polymer gel electrolytes: Investigation on their conductivity and characterization. Acta Physica Polonica A 129(4):621-624, 2016. https://doi.org/10.12693/APhysPolA.129.621

[16] M. F. Hassan, F. F. Awang, N. S. N. Azimi, C. K. Sheng. Starch $/ \mathrm{MgSO}_{4}$ solid polymer electrolyte for zinc carbon batteries and its application in a simple circuit. Journal of Sustainability Science and Management 15(8):1-8, 2020.

https://doi.org/10.46754/jssm.2020.12.001. 
[17] S. B. Aziz. $\mathrm{Li}^{+}$ion conduction mechanism in poly ( $\varepsilon$-caprolactone)-based polymer electrolyte. Iranian Polymer Journal 22(12):877-883, 2013. https://doi.org/10.1007/s13726-013-0186-7.

[18] D. Hambali, Z. Zainnuddin, I. Supa'at, Z. Osman. Studies of ion transport and electrochemical properties of plasticized composite polymer electrolytes. Sains Malaysiana 45(11):1697-1705, 2016.

[19] P. C. Sekhar, P. N. Kumar, A. K. Sharma. Effect of plasticizer on conductivity and cell parameters of $\left(\mathrm{PMMA}+\mathrm{NaClO}_{4}\right)$ polymer electrolyte system. IOSR Journal of Applied Physics (IOSR-JAP) 2(4):1-6, 2012. https://doi.org/10.9790/4861-0240106

[20] S. B. Aziz, O. G. Abdullah, M. A. Rasheed, H. M. Ahmed. Effect of high salt concentration (HSC) on structural, morphological, and electrical characteristics of chitosan based solid polymer electrolytes. Polymers 9(6), 2017. https://doi.org/10.3390/polym9060187

[21] C. L. Luchese, P. Benelli, J. C. Spada, I. C. Tessaro. Impact of the starch source on the physicochemical properties and biodegradability of different starch-based films. Journal of Applied Polymer Science 135(33):1-11, 2018. https://doi.org/10.1002/app.46564.

[22] B. Chatterjee, N. Kulshrestha, P. N. Gupta. Preparation and characterization of lithium ion conducting solid polymer electrolytes from biodegradable polymers starch and PVA. International Journal of Engineering Research and Applications 5:116-131, 2015.

[23] R. Alves, M. M. Silva. The influence of glycerol and formaldehyde in gelatin-based polymer electrolytes. Molecular Crystals and Liquid Crystals 591(1):64-73, 2014.

https://doi.org/10.1080/15421406.2013.822739.

[24] R. Alves, J. P. Donoso, C. J. Magon, et al. Solid polymer electrolytes based on chitosan and europium triflate. Journal of Non-Crystalline Solids 432:307-312, 2016. https://doi.org/10.1016/j.jnoncrysol.2015.10.024

[25] H. M. A. Herath, V. A. Seneviratne. Electrical and thermal studies on sodium based polymer electrolyte. Procedia Engineering 215:124-129, 2017. https://doi.org/10.1016/j.proeng.2018.02.089.

[26] S. Brutti, et al. Ionic liquid electrolytes for room temperature sodium battery systems. Electrochimica Acta 306:317-326, 2019. https://doi.org/10.1016/j.electacta.2019.03.139.

[27] P. K. Nayak, L. Yang, W. Brehm, P. Adelhelm. From lithium-ion to sodium-ion batteries: Advantages, challenges, and surprises. Angew Chem International Ed England 57(1):102-120, 2018. https://doi.org/10.1002/anie.201703772
[28] J. Mei, Y. Yuan, Y. Wu, Y. Li. Characterization of edible starch-chitosan film and its application in the storage of Mongolian cheese. International Journal Biological Macromolecules 57:17-21, 2013. https://doi.org/10.1016/j.ijbiomac.2013.03.003

[29] M. F. Hassan, S. Z. M. Yusof. Poly(acrylamide-coacrylic acid)-zinc acetate polymer electrolytes: Studies based on structural and morphology and electrical spectroscopy. Microscopy Research 02(02):30-38, 2014. https://doi.org/10.4236/mr.2014.22005

[30] F. F. Awang, K. H. Kamarudin, M. F. Hassan. Effect of sodium bisulfite on corn starch solid polymer electrolyte. Malaysian Journal of Analytical Science 25(2):224-233, 2021.

[31] S. B. Aziz, M. H. Hamsan, W. O. Karim, et al. Study of impedance and solid-state double-layer capacitor behavior of proton $\left(\mathrm{H}^{+}\right)$-conducting polymer blend electrolyte-based CS:PS polymers. Ionics 26(9):4635-4649, 2020. https://doi.org/10.1007/s11581-020-03578-6

[32] N. Angulakshmi, D. J. Yoo, K. S. Nahm, et al. $\mathrm{MgAl}_{2} \mathrm{SiO}_{6}$-incorporated poly(ethylene oxide)-based electrolytes for all-solid-state lithium batteries. Ionics 20(2):151-156, 2013. https://doi.org/10.1007/s11581-013-0985-z.

[33] M. F. Hassan, A. N.S.N, K. H. Kamarudin, C. K. Sheng. Solid polymer electrolytes based on starchmagnesium sulphate: Study on morphology and electrical conductivity. ASM Science Journal Special Issue pp. 17-28, 2018

[34] S. B. Aziz, M. A. Brza, K. Mishra, et al. Fabrication of high performance energy storage EDLC device from proton conducting methylcellulose: dextran polymer blend electrolytes. Journal of Materials Research and Technology 9(2):1137-1150, 2020. https://doi.org/10.1016/j.jmrt.2019.11.042

[35] M. F. Z. Kadir, S. R. Majid, A. K. Arof. Plasticized chitosan-PVA blend polymer electrolyte based proton battery. Electrochimica Acta 55(4):1475-1482, 2010. https://doi.org/10.1016/j.electacta.2009.05.011

[36] M. N. Z. M. Sapri, A. H. Ahmad. Conductivity and FTIR studies on PEO-NaCF${ }_{3} \mathrm{SO}_{3}$ solid polymer electrolyte films. Science Letters 10(1):11-13, 2016.

[37] N. N. A. Amran, N. S. A. Manan, M. F. Z. Kadir. The effect of $\mathrm{LiCF}_{3} \mathrm{SO}_{3}$ on the complexation with potato starch-chitosan blend polymer electrolytes. Ionics 22(9):1647-1658, 2016. https://doi.org/10.1007/s11581-016-1684-3. 